\title{
Raum für neue Ideen
}

Derzeit ändert sich vieles. Das gilt auch für die Keramik-Community, wie Sie auf den folgenden Seiten nachlesen können. In den vergangenen Wochen haben viele Organisatoren beschlossen, ihre Konferenzen, Messen und andere Veranstaltungen auf das Ende dieses Jahres oder sogar auf 2021 zu verschieben. Nur noch sehr wenige verbleiben in unserem Veranstaltungskalender. Daher alle Achtung vor den Organisatoren von Veranstaltungen wie dem Internationalen Feuerfest-Kolloquium und dem Team von AM Ceramics, die beide jeweils eine neue Videokonferenz einführen werden oder den Organisatoren der Formnext, die kürzlich angekündigt haben, dass die Formnext 2020 auch weiterhin im Messekalender bleiben wird.

Bei diesen Veranstaltungen sind viele Änderungen zu erwarten, von umfassenden Hygienekonzepten bis hin zur Digitalisierung von Inhalten. Und die Umsetzung wird nicht einfach sein. Deshalb müssen alle in der Keramikindustrie zusammenstehen und neue und kreative Ideen unterstützen, mit denen diese Krise überstanden werden kann. Die Branche ist eine sehr enge Gemeinschaft mit wenigen und daher umso wichtigeren Fachveranstaltungen, die hoffentlich unseren Veranstaltungskalender in 2021 wieder füllen werden.

Hierbei möchten wir auch die Gelegenheit nutzen, eine Neuerung von unserer Seite vorzustellen: Wir haben uns der Herausforderung ,Digitale Kommunikation' gestellt und ein neues Videoformat auf unserer LinkedIn-Seite eingeführt. Mit ,Ceramic News in 90 Seconds' halten wir Sie mit kurzen Videos über aktuelle Ereignisse auf dem Laufenden. Die Details können Sie auf unserer Website und wie immer in der Keramischen Zeitschrift nachlesen.

Wir wünschen viel Vergnügen beim Anschauen!

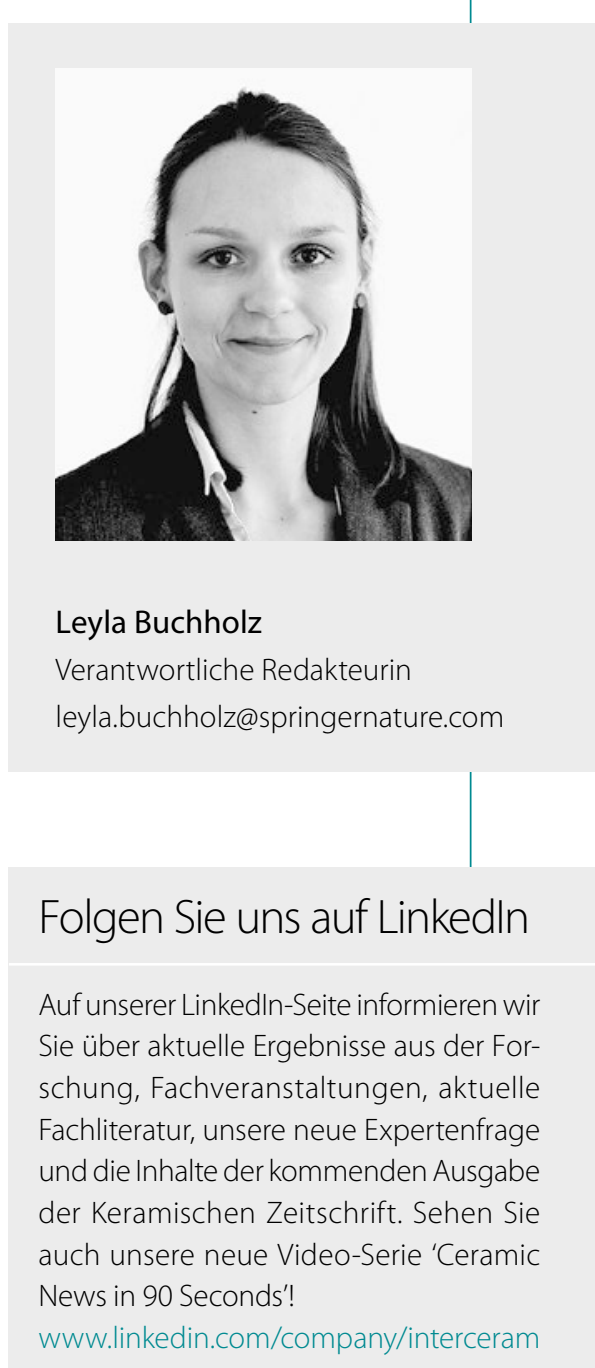

